\title{
A Rare Case of Non-Functioning Pituitary Macroadenoma (NFMA)
}

\author{
O. Rezaee1, R. Salar ${ }^{*}$, R. Jabari1 ${ }^{1}$ A. Shams Akhtari2 \\ ${ }^{1}$ Neurosugery Department, Shahid Beheshti University of Medical Sciences, Tehran, Iran \\ ${ }^{2}$ Emergency Department, Shahid Beheshti University of Medical Sciences, Tehran, Iran \\ Email: ${ }^{\text {amin.may1981@gmail.com }}$
}

Received 30 May 2014; revised 31 June 2014; accepted 29 July 2014

Copyright (C) 2014 by authors and Scientific Research Publishing Inc.

This work is licensed under the Creative Commons Attribution International License (CC BY). http://creativecommons.org/licenses/by/4.0/

c) (i) Open Access

\begin{abstract}
NFMAs are benign tumors that do not produce any biologically active hormones and exceed 10 $\mathrm{mm}(0.39 \mathrm{in})$ in size. Although NFMAs are benign in origin, mass effects may lead to serious clinical symptoms such as visual impairments, chronic headache, and pituitary insufficiency. The authors describe a 51-year-old woman who had a NFMA $(35 \times 24 \times 25 \mathrm{~mm})$. The vision was reduced to $7 / 10$ in the both eyes. A transnasal transsphenoidal surgery was performed and the tumor was successfully resected. Postoperatively, the patient had visual $(9 / 10)$ and headache improvement. This case highlights a rare presentation of non-functioning pituitary macroadenoma.
\end{abstract}

\section{Keywords}

Non-Functioning Pituitary Macroadenoma (NFMA), Transnasal Transsphenoidal Surgery, Vision, Headache

\section{Introduction}

The prevalence of pituitary tumors has been reported to be as high as $94 \pm 19.3$ cases per 100,000 population [1]. Most of these tumors are histological benign and represent $10 \%-12 \%$ of all intracranial neoplasms [2] [3]. Pituitary tumors can be classified on the basis of their size, and this has been of considerable interest to the neurosurgeon. They have been classified into microadenomas ( $<10 \mathrm{~mm}$ size), macroadenoma ( $>10 \mathrm{~mm}$ size) and giant pituitary adenomas ( $>40 \mathrm{~mm}$ size) [4]. Also pituitary adenomas are classified according to functional status. If a pituitary adenoma makes hormones it is called functional. If it doesn't make any hormones it is called non-functional [5]. Non-functioning pituitary macroadenomas (NFMAs) are common tumors of the anterior pituitary and are the most frequent indication for pituitary surgery [6]-[8]. Although NFMAs are benign in origin,

*Corresponding author.

How to cite this paper: Rezaee, O., Salar, R., Jabari, R. and Shams Akhtari, A. (2014) A Rare Case of Non-Functioning Pituitary Macroadenoma (NFMA). Open Journal of Modern Neurosurgery, 4, 150-153.

http://dx.doi.org/10.4236/ojmn.2014.43026 
mass effects may lead to serious clinical symptoms such as visual impairments, chronic headache, and pituitary insufficiency [9] [10]. The initial management of large nonfunctioning pituitary macroadenomas is surgical debulking to relieve mass effects on adjacent structures, principally the optic chiasm [6]. We recently treated a patient who had a pituitary macroadenoma treated successfully by endoscopic transnasal transsphenoidal approach.

\section{Case Report}

A 51-year-old woman presented with complaints of generalized headaches and worsening vision in both eyes for three months. The vision was reduced to $7 / 10$ in the both eyes. Magnetic resonance imaging (MRI) showed a pituitary macroadenoma $(35 \times 24 \times 25 \mathrm{~mm}$ ) located in sellar region (Figure 1).

Endocrinological evaluation (baseline hormonal assay) showed PRL: $580 \mathrm{IU} / \mathrm{mL}$ (normal level 102 - 496), testosterone: $0.022 \mathrm{ng} / \mathrm{mL}$ (normal level 1.5 - 7), LH: $12.1 \mathrm{mU} / \mathrm{mL}$ (normal level 2.4 - 12.6) and FSH: 29.1 $\mathrm{mU} / \mathrm{mL}$ (normal level 3.5 - 12.5), T4: $9.2 \mathrm{mcg} / \mathrm{mL}$ (normal level 5.1 - 14), TSH: $1.5 \mathrm{IU} / \mathrm{mL}$ (normal level 0.27 4.2), Cortisol: $180 \mathrm{ng} / \mathrm{mL}$ (normal level 54.9 - 287.5), GH: $0.02 \mathrm{ng} / \mathrm{mL}$ (normal level 0 - 18), ACTH: 38.15 $\mathrm{pg} / \mathrm{mL}$ (normal level 3.6 - 60.5), IGF1: $128.1 \mathrm{pg} / \mathrm{mL}$ (normal level 88.3 - 209.9). According hormone testing, the tumor was non-functional. A transnasal transsphenoidal surgery was performed. Postoperative MRI images showed that the tumor was successfully resected (Figure 2). Postoperatively, the patient had visual (9/10) and headache improvement.

\section{Discussion}

This case highlights a rare presentation of non-functioning pituitary macroadenoma (NFMA). NFMAs are be-

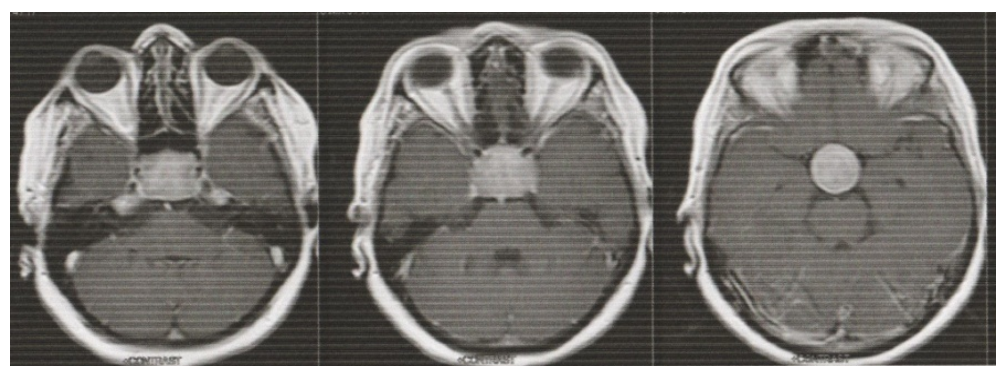

(a)

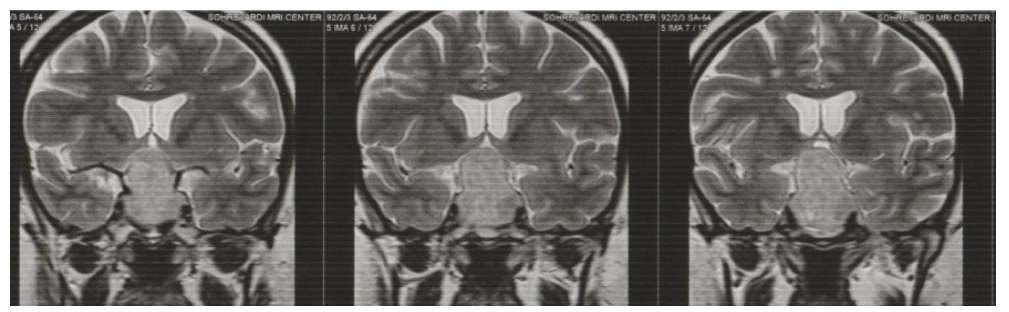

(b)

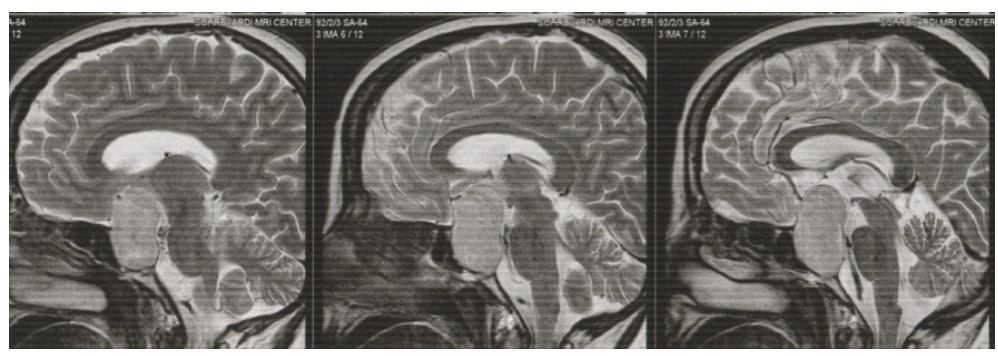

(c)

Figure 1. Axial (a), coronal (b) and sagittal (c) peroperative MRI images showing a lesion in the sellar region. 


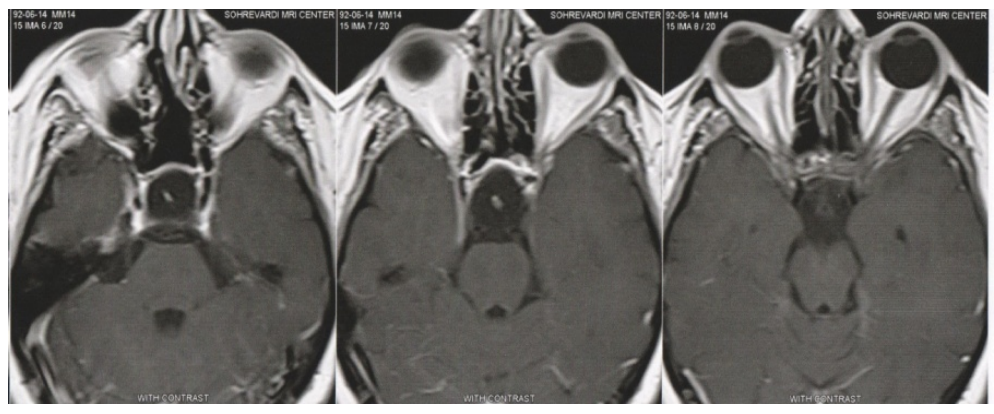

(a)

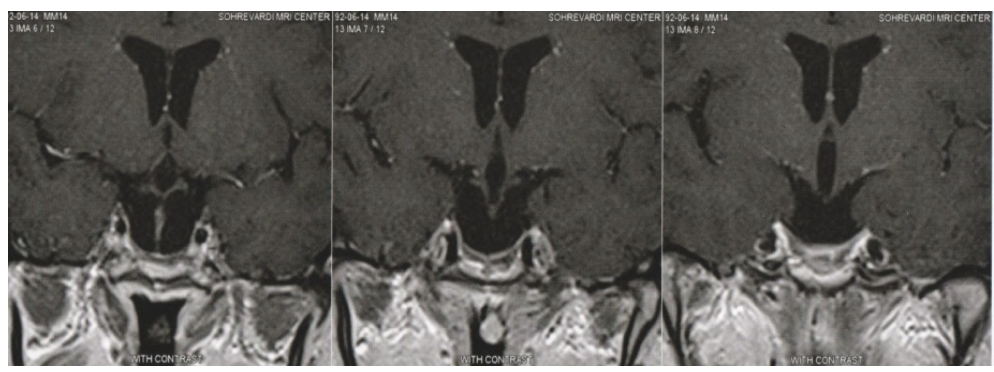

(b)

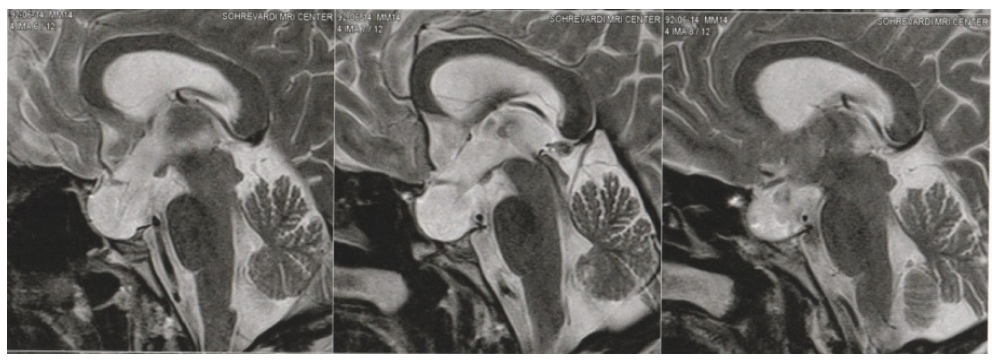

(c)

Figure 2. Axial (a), coronal (b) and sagittal (c) postoperative MRI images showing the tumor was successfully resected.

nign tumors that do not produce any biologically active hormones and exceed $10 \mathrm{~mm}$ (0.39 in) in size [11]. The initial presentation of nonfunctioning pituitary adenomas depends largely on size and growth pattern of the tumor [12]. Typically, macroadenomas cause bitemporal field defects, explained by the anatomy of the visual pathways in the chiasm: the nerves that connect the brain to the eyes (the optic nerves) and to the muscles that move the eyes pass near the pituitary gland. An enlarged pituitary can press on these nerves and affect vision. However, depending on the growth pattern of the tumor, there may be an asymmetry between the visual field defects of the two eyes [13].

Our patient had visual deterioration on clinical examination. This loss of visual acuity probably reflects the large size of the tumor. At the time of initial diagnosis, visual field defects are detected in $60 \%-80 \%$ of NFMA patients [10] [14]. Surgical approaches to the sellar lesions have undergone considerable refinement during the last century. Visual recovery has been demonstrated in the first days after surgical treatment [15] [16] and is caused by decompression of the visual pathways, leading to a restoration of signal conduction. Usually, microsurgical treatment is recommended for large-to-giant pituitary adenomas using a transsphenoidal approach because of minimal surgical morbidity [1]. In this case, we chose the less invasive endoscopic transnasal transsphenoidal approach to deal with the 3rd ventricular portion of the tumor and successfully decompressed the tumor. A combined transnasal and simultaneous transsphenoidal endoscopic approach is a safe and useful option for patients with a pituitary macroadenomain which size, configuration, consistency or prior treatment precluded removal by one approach alone. This technique may achieve the goal of tumor resection with minimal invasion and reduce the need for multiple operations. 


\section{References}

[1] Guo, F.Y., Li, Z.H., Song, L.J. and Liu, X.Z. (2013) One Exceedingly Rare Co-Existence of Pituitary Adenoma with Hydrocephalus and Cerebral Aneurysm: Case Report and Literature Review. Life Science Journal, 10, 1719-1723.

[2] Kim, Y.Z., Song, Y.J. and Kim, H.D. (2005) Preliminary Surgical Results of Open Sella Method with Intentionally Satged Trans-Sphenoidal Approach for Patients with Giant Pituitary Adenomas. Journal of Korean Neurosurgical Society, 37, 16-19.

[3] Oruckaptan, H.H., Senmevism, O., Ozcan, O.E. and Ozgen, T. (2000) Pituitary Adenomas Results of 684 Surgically Treated Patients and Review of the Literature. Surgical Neurology, 53, 211-219. http://dx.doi.org/10.1016/S0090-3019(00)00171-3

[4] Sinha, S., Sarkar, C., Sharma, B.S. and Mahapatra, A.K. (2008) Giant Pituitary Adenomas: Surgical Outcome in a Series of 127 Cases. Pan Arab Journal of Neurosurgery, 12, 60-66.

[5] Jane, J.A. and Laws, E.R. (2002) Surgical Management of Pituitary Adenoma. Singapore Medical Journal, 43, 318323.

[6] Boelaert, K. and Gittoes, N.J.L. (2001) Radiotherapy for Non-Functioning Pituitary Adenomas. European Journal of Endocrinology, 144, 569-575. http://dx.doi.org/10.1530/eje.0.1440569

[7] Gittoes, N.J. (1998) Current Perspectives on the Pathogenesis of Clinically Non-Functioning Pituitary. Journal of Endocrinology, 157, 177-186. http://dx.doi.org/10.1677/joe.0.1570177

[8] Shimon, I. and Melmed, S. (1997) Pituitary Tumor Pathogenesis. Journal of Clinical Endocrinology and Metabolism, 82, 1675-1681.

[9] Dekkers, O.M., Hammer, S., Wdw Keizer, R.J., Roelfsema, F., Schutte, P.J., Smit, J.W.A., Romijn, J.A. and Pereira, A.M. (2007) The Natural Course of Non-Functioning Pituitary Macroadenomas. European Journal of Endocrinology, 156, 217-224. http://dx.doi.org/10.1530/eje.1.02334

[10] Wichers-Rother, M., Hoven, S., Kristof, R.A., Bliesener, N. and Stoffel-Wanger, B. (2004) Non-Functioning Pituitary Adenomas: Endocrinological and Clinical Outcome after Transsphenoidal and Transcranial Surgery. Experimental and Clinical Endocrinology and Diabetes, 112, 323-327. http://dx.doi.org/10.1055/s-2004-820914

[11] Ferrante, E., Ferraroni, M., Castringnano, T., Menicatti, L., Anagni, M., Reimondo, G., et al. (2006) Non-Functioning Pituitary Adenoma Database: A Useful Resource to Improve the Clinical Management of Pituitary Tumors. European Journal of Endocrinology, 155, 823-829. http://dx.doi.org/10.1530/eje.1.02298

[12] Soto-Ares, G., Cortet-Rudelli, C., Assaker, R., et al. (2002) MRI Technique in the Optimal Therapeutic Strategy of Nonfunctioning Pituitary Adenomas. European Journal of Endocrinology, 146, 179-186. http://dx.doi.org/10.1530/eje.0.1460179

[13] Scarone, P., Losa, M., Mortini, P. and Giovanelli, M. (2006) Obstructive Hydrocephalus and Intracranial Hypertension Caused by a Giant Macroprolactinoma. Prompt Response to Medical Treatment. Journal of Neuro-Oncology, 76, 5154. http://dx.doi.org/10.1007/s11060-005-2319-0

[14] Comtois, R., Beauregard, H., Somma, M., Serri, O., Aris-Jilwan, N. and Hardy, J. (1991) The Clinical and Endocrine Outcome to Trans-Sphenoidal Microsurgery of Nonsecreting Pituitary Adenomas. Cancer, 68, 860-866. http://dx.doi.org/10.1002/1097-0142(19910815)68:4<860::AID-CNCR2820680431>3.0.CO;2-4

[15] Jakobsson, K.E., Petruson, B. and Lindblom, B. (2002) Dynamics of Visual Improvement Following Chiasmal Decompression. Quantitive Pre- and Postoperative Observations. Acta Ophthalmologica Scandinavica, 80, 512-516. http://dx.doi.org/10.1034/j.1600-0420.2002.800510.x

[16] Kerrison, J.B., Lynn, M.J., Baer, C.A., Newman, S.A., Biousse, V. and Newman, N.J. (2000) Stage of Improvement in Visual Field after Pituitary Tumor Resection. American Journal of Ophthalmology, 130, 813-820. http://dx.doi.org/10.1016/S0002-9394(00)00539-0 
Scientific Research Publishing (SCIRP) is one of the largest Open Access journal publishers. It is currently publishing more than 200 open access, online, peer-reviewed journals covering a wide range of academic disciplines. SCIRP serves the worldwide academic communities and contributes to the progress and application of science with its publication.

Other selected journals from SCIRP are listed as below. Submit your manuscript to us via either submit@scirp.org or Online Submission Portal.
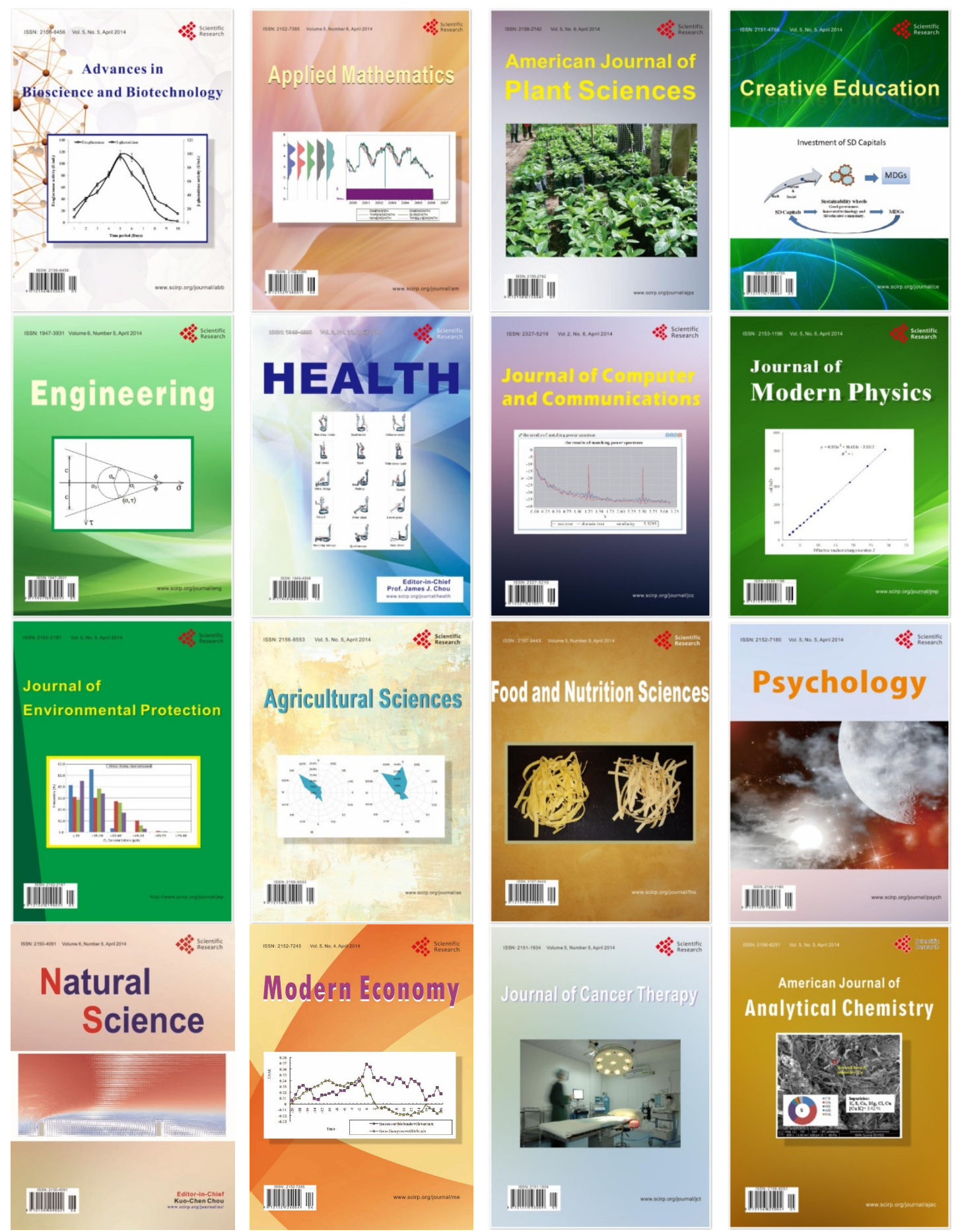